\title{
Urine as a communicator in a New World primate, Saimiri sciureus
}

\author{
DOUGLAS K. CANDLAND, EVAN S. BLUMER, and MICHAEL D. MUMFORD \\ Bucknell University, Lewisburg, Pennsylvania 17837
}

\begin{abstract}
New World primates face problems of communication distinct from those of their Old World counterparts. We suspected that the odor of urine might serve the function of communicating information among animals or troops. Two studies were conducted with Saimiri sciureus; one examined, in a laboratory enclosure, the influence of breeding season, social condition, area, and whether the urine was from known animals or from strangers, and the second measured, in a seminatural rain forest, responses to our spreading Saimiri urine on selected sites. Enclosure and field produce the same general patterns of frequencies of behavior for urination, the urine wash and kick wash, and rubbing. The chief difference in behavior between the environments is found in the frequency of sneezing. Season (breeding or nonbreeding) is the most effective variable producing this general pattern: During the breeding season, males urine-wash throughout the enclosure or troop range, whereas during the nonbreeding season, this behavior is restricted in location, at least in the enclosure. At this time, females increase their frequencies of sniffing and rubbing. Many of these behaviors are observed only in special locations of the enclosure. The results show that Saimiri respond differently to the urine of known and foreign animals, depending upon the season and whether they are with members of their own sex or both sexes. It is suggested that primates not equipped with specialized organs for scent marking may use urine opportunistically to communicate.
\end{abstract}

A significant number of species of New World primates (Platyrrhini) may be characterized by their heavy investment of time in foraging, a seemingly casual form of troop membership and cohesion, a clearly defined breeding season, and a strong preference for arboreal movement (Hill, 1960, 1962; Moynihan, 1976; Napier \& Napier, 1967; Walker, 1975). These characteristics would appear to require frequent communication to one another regarding the location of individual animals in order to maintain troop cohesion. Visual communication is limited by the dense flora in which New World primates reside. Auditory communication, while common (Sebeok, 1968; Smith, 1977; Winter, Ploog, \& Latta,

\footnotetext{
Work of this scope cbviously required the participation of many students who have been associated with the Bucknell animal behavior program. Their ideas are plentiful in this paper, and the extent of their labor is obvious. Deserving special mention are: Greg Lorinc, who began the work; Peter Judge and Evan Blumer, who took responsibility for the work at Monkey Jungle; and David Milne, who invented statistical models equipped to evaluate the data. We thank also Roy Fontaine, Jeffrey French, John Ruch, Kim Ahrensen, Nancy Feinstein, Betty Fine, Shanna Brandow, Tom Lapham, Caren Rosenthal, Tim Ainslie, Barbara Farrell, Bill McShea, Kevin O'Connor, Kim Schneider, Tim Jensen, and Jon Jensen. Mary Candland prepared the artwork and Mary Nornhold clarified the text. Drafts of this paper were much improved by the unsparing attention of our colleagues Nancy Cain, Jerry Eberhart, Owen Floody, Alan Leshner, and Mike Pereira. We are very grateful to the late Frank DuMond and to Mary DuMond for making the facilities at Monkey Jungle available to us over a long period and for their interest in and encouragement of this work.
}

1966), is not always a satisfactory means of communicating location. Acoustic calls alert not only members of one's own troop, but also potential predators and members of other troops. Moreover, the areas inhabited by New World primates contain many other animals that give acoustic calls, a cacophony that lends ambiguity to auditory signaling.

In an apparent adaptation to enhance communication, some species of the Platyrrhini have developed specialized glands that secrete pheromones. The advantage of chemical communication is that the sender need not remain with the stimulus, as is necessary when either auditory or visual communication is employed. The message deposited may alert fellow troop members to the recent location of the sender without necessarily alerting potential predators or strangers as well. Chemical communication is long-lasting compared with visual and auditory signals. This is a characteristic that is useful if an animal moves about and explores large territories, as most Platyrrhini do. It is now well established that some Platyrrhini (and some Tarsioidea as well) use olfaction for a range of communicatory activities through the secretion of pheromonal material from specialized glands (Epple, 1974a, 1974b; Thiessen \& Rice, 1976).

Animals that have not evolved specialized glands for pheromone secretion have available other means of marking-excretory rather than secretory ones. Defecation, urination, and sweat excretion are obvious ways by which animals might leave olfactory communicators. This paper investigates the possibility 
that urine is used by a common cebid, Saimiri sciureus (the squirrel monkey), to communicate information regarding its location and its reactions to environmental events (such as unknown animals) and internal events (sexual preparedness). Possibly, the content of the urine permits communication of changes in the animal's physical and emotional states. The work of Jones and Nowell $(1973,1974)$ supports the possibility of a hormone-dependent pheromonal factor in urine. They demonstrated the presence in male mouse urine of a pheromonal factor that discourages investigation of areas marked with such urine. The aversive nature of this pheromonal factor was found to increase with increases in androgen levels.

Among the Callitrichidae, urine marking appears to be involved in the establishment and maintenance of social dominance. Epple (1974a) believes that dominant and submissive animals may be characterizable by odors that signal their social status. She has also suggested (1974b) that olfactory communication may be used to control intraspecific aggression, a suggestion corroborated by other students of marmoset behavior (Stevenson, 1980; Vogt, 1980). Milton (1975) investigated urine marking by Alouatta palliata (the howler monkey) living on Barro Colorado Island in the Panama Canal Zone and found that adults of both sexes urine-marked. She suggested that, among other uses, urine washing is used as a means of identifying individuals within the troop.

Squirrel monkeys (Saimiri sciureus) also show a complex set of behaviors involving urine marking. The primary urine-marking behavior of Saimiri is the urine wash. The animal appears to urinate on the palm of the hand and to wipe the hand against the sole of the foot. Occasionally, animals are observed to rub both palms together or to rub the throat (Hopf et.al., 1974).

Although urine washing in Saimiri has been observed by almost all who study them, little can be said about its function. Schmidt and Seitz (cited in Epple, 1974b) interpreted the urine wash in Saimiri as serving a thermoregulatory function, while Castell and Maurus (1967) suggested that its function was to keep the hands and feet clean and moist. Both Castell and Heinrich (1971) and Latta, Hopf, and Ploog (1967) have suggested that there are olfactory cues present in the urine that communicate the reproductive condition of the female. Thorington $(1968$, p. 80$)$, to the contrary, concluded that there was no olfactory or other significance to the urine wash-at least among free-ranging animals. Baldwin $(1968,1969)$ suggested that the urine wash was used for olfactory marking in females, although it might also be used among males as a displacement behavior. He considered the possibility that the urine of the dominant male might inhibit the hormonal activity of an already submis- sive male through an olfactory-hypothalamic-pituitary pathway (1968, pp. 289-298). Castell and Heinrich (1971) and Talmage-Riggs and Anschel (1973) have shown that the occurrence of the urine wash is correlated positively with dominance: the higher the rank of the animal, the more urine washes are observed. Talmage-Riggs and Anschel (1973) suggest that the correlation may be due to the possible increased frequency of eating and drinking in dominant animals. Bolwig (cited in Epple, 1974b) and Seitz (1969) have both suggested that one of the functions of urine marking is the production of odiferous trails that assist the animal to orient itself within the home range. While examining behavioral and sexual behavioral patterns in possible subspecies of Saimiri, Hennessy, Coe, Mendoza, Lowe, and Levine (1978) found evidence that these primates do use the odor of urine. In their discussion, these authors speculate that "while foraging in dense vegetation, members of a squirrel monkey group may lose visual or even auditory contact with other group members. Under these conditions scent marks on branches could provide a path for isolated animals to follow" (p. 66).

In order to isolate the functional significance of urine deposited by Saimiri, we elected to relate several environmental factors (season of the year, sex, area in which the behavior occurred, the availability of urine from other animals or those of one's own colony, and whether the animals were freely ranging or enclosed) with behaviors associated with the use of urine as a possible communicator (urination, the urine wash, urine kick wash, rubbing, sneezing, and sniffing). Our purpose was to determine how urine affects Saimiri behavior.

\section{EXPERIMENT 1}

The goal of this experiment was to determine the relationship between several environmental factors and the frequency of behaviors related to the depositing of urine. Experiment 1 assessed these relationships with animals living in a laboratory enclosure.

\footnotetext{
Method

Subjects. Four female and four male Saimiri sciureus (source: Iquitos, Peru) were used. They had been housed together for 4 years in a laboratory enclosure located at Bucknell University, Lewisburg, Pennsylvania. The seasonal cycle at this latitude $\left(40^{\circ} 58^{\prime} \mathrm{N}\right)$ produces a November-January breeding season, with the males becoming fatted in October (DuMond \& Hutchinson, 1967). Lighting was controlled by a seasonal astronomical timer that approximated the seasonal variations of Lima, Peru. Births occur in April and May. The breeding cycle of freely ranging Saimiri in more southern latitudes is not the same. Two males died during the period between the breeding and nonbreeding seasons, thus changing the number of animals available for observation in the nonbreeding season.

The male weights ranged from 1 to $1.2 \mathrm{~kg}$ during the breeding season and from .7 to $.8 \mathrm{~kg}$ during the nonbreeding season. Female weights ranged from .6 to $.8 \mathrm{~kg}$. The animals were 5 to 7 years old at the onset of these observations. They were born and reared in the laboratory enclosure.
} 
The males of the group had established a recognizable dominance order by following the pattern of Saimiri males using the genital display toward one another, as described by Candland, 1971, Candland et al., 1970, and Ploog \& McClean, 1963. Because the group had lived together for several years, displays were seen rarely. Dominance was most easily observed in the independence of movement permitted individual animals by others. The animals wore color-coded beads as necklaces to assist identification.

Environment. The Saimiri were observed in their permanent housing unit. The enclosure was $3 \times 3 \times 3 \mathrm{~m}$. The floor was covered with a $10-\mathrm{cm}$ bedding of cedar chips. Ropes were placed at $1-\mathrm{m}$ intervals both horizontally and vertically, forming 27 equal areas within the enclosure. These ropes were attached to permanent hooks so that they could be changed in accordance with the experimental design that will be described. The temperature in the room containing the enclosure was maintained at $23^{\circ} \mathrm{C}$, although the humidity varied between $15 \%$ and $45 \%$. The animals were provided with Purina Monkey Chow, supplemented with apples and oranges. Both food and water were available ad lib.

Certain aspects of the experimental design called for males to be isolated from females. When so required, either the male or female animals were placed in another enclosure, identical to the one just described. Although located in different rooms, the two enclosures were connected by a wire-mesh runway $.4 \times .4 \times$ $4.1 \mathrm{~m}$. On days when the animals were not to be observed, they were maintained individually in $.6 \times .6 \times .4 \mathrm{~m}$ cages in a room that was beyond the auditory range of those in the enclosure.

Procedure. Six main independent factors were used in the study: (1) The time of day at which the observations were made, either midmorning or midafternoon. (2) The sex of the animal being observed. (3) The condition of the ropes in the enclosure-Ropes designated as "own" were those on which the colony had lived for years and on which excretions had been deposited. "Fresh" ropes were new and unmarked. "Recently marked" were those on which the animals had lived for only $4 \mathrm{~h}$. "Foreign" ropes were marked by the experimenters with urine of Saimiri unknown to the colony. This urine was selected from that which had been collected and frozen over a period of several years when urine samples had been taken from these and other Saimiri for endocrine assays. It is possible that some of this urine was that of Saimiri with whom the subjects may have had contact no more recently than 5 years previously or that its odorous qualities had changed through freezing. (4) The social group of the Saimiri-males grouped alone, females grouped alone, males and females considered independently in a group of both sexes. (5) The area of the enclosure-The ropes were placed to form three horizontal and three vertical layers. This placement yielded nine equal-sized areas, as seen from above the enclosure. The corner areas and the central area were labeled as Areas 1 to 5 clockwise, with Area 5 being the center area. If an animal was observed on the rope separating one labeled area from a contiguous area, that animal was considered to be in the labeled area. This procedure eliminated only the time when an animal was in transit (always by jumping) from one area to another. (6) The season-breeding (January) or nonbreeding (June)-in which the observations were made.

When it was necessary to change ropes, the surface area of the enclosure was scrubbed with a mild disinfectant in order to remove or disguise extant odors. When it was necessary to mark the ropes with the urine of foreign animals, we coated the top of the ropes with $50 \mathrm{ml}$ or urine from each of four individual male samples. The urine was applied to the ropes with surgical cotton so that urine from one sample was applied to each of the areas $(1-4)$. Procedures were identical during the breeding and nonbreeding seasons. When the ropes were marked by us, urine from a past breeding season was used in the breeding-season observations, and urine from a past nonbreeding season was used in the nonbreeding-season study.

The schedule of observations was arranged so that each of the main factors was varied systematically with each of the remaining factors. Of these factors, two were dependent upon the subjects (sex, areas in which the behavior occurred), two were independent of the subjects and the experimenters (time of day, season of year), and two were varied by us (social group condition, characteristics of the rope used in the enclosure).

The observers were 18 undergraduate students who volunteered their time either in January between college sessions or during NSF summer undergraduate research participation. Eleven served during the January breeding season, and seven during the June nonbreeding season. Instructions on observations were given, and 6 to 10 practice hours of recording were arranged. Reliability was measured by correlation coefficients between behaviors, with each observer rotating among animal subjects. During the breeding season, initial reliabilities were in the .6 range and increased to a range of .70 to .90 , depending upon the behavior. Urination and urine washes had the highest reliabilities, and rubbing had the lowest; sniffing and sneezing were between these extremes. During the nonbreeding season, the reliabilities were higher at the low end, but similar at the upper, .90 , level. Any problems encountered in the behavior-scoring task were similar for both groups of observers.

One hundred seconds before the beginning of a scheduled observation, the animals were herded from the holding enclosure, through the runway, and into the home enclosure. Two 2,600sec observation sessions were conducted, the first at 9 a.m. and the second at 2 p.m., on each day of the 16-day period for both the breeding and nonbreeding seasons. Each observation session consisted of four subperiods of $500 \mathrm{sec}$ each, with a $200-\mathrm{sec}$ interval between trials. During this intertrial interval, arranged principally to maintain alertness on the part of the observers, the observers were encouraged to leave the testing area quietly and to return within $120 \mathrm{sec}$. During the observation periods, each observer was responsible for one animal. The responsibilities for individual animals were rotated among observers. A slight click was sounded every $5 \mathrm{sec}$. by a Foringer timing apparatus as a signal for the observer to record the behavior and the location of the animal being observed.

It should be noted that the position of the animals in the enclosure is probably influenced by factors other than those arranged in this experimental design. First, the enclosure's walls are not identical. The side facing Areas 1 and 2 has a solid wall, while the remaining sides have viewing windows. Over the years, we have noted that the animals prefer the side with a full wall, at least when viewers are present. Second, viewing was done from three sides and the viewers' presence may well have prompted

Table 1

\begin{tabular}{|c|c|c|}
\hline Behavior & $\begin{array}{c}\text { Abbrev- } \\
\text { iation }\end{array}$ & $\begin{array}{c}\text { Description } \\
\text { (Hopf et al., 1974) }\end{array}$ \\
\hline Urine Wash & Uw & $\begin{array}{l}\text { A few drops of urine on the palm } \\
\text { of one hand rubbed against the sole } \\
\text { of the ipsilateral foot. }\end{array}$ \\
\hline Urination & Ur & $\begin{array}{l}\text { No special posture, base of tail may } \\
\text { be lifted - a steady stream of urine. }\end{array}$ \\
\hline Urine Kick Wash & Ukw & $\begin{array}{l}\text { Urinating on the homolateral hand } \\
\text { and foot, then the foot is thrust up } \\
\text { under the armpit and out } 3-4 \text { times. }\end{array}$ \\
\hline Sneeze & $\mathrm{Sz}$ & $\begin{array}{l}\text { Nose either against an object or in } \\
\text { the air while repeatedly making a } \\
\text { "sneeze" noise. }\end{array}$ \\
\hline Sniff & Sf & $\begin{array}{l}\text { Nose either against an object or in } \\
\text { the air while making a "sniffing" } \\
\text { noise. }\end{array}$ \\
\hline Rub & $\mathrm{Ru}$ & $\begin{array}{l}\text { Rubbing or rolling a portion of the } \\
\text { body against an object. }\end{array}$ \\
\hline
\end{tabular}

Note-The $U k w$ is considered similar to $U w$, for the only functional difference between the two behaviors is that the Ukw, unlike the ordinary $U w$, produces a spray that can be interpreted as having the function of increasing the surface area of the urine sample and the urine's effective volatility. 
certain animals to prefer the walled side, that facing Areas 1 and 2. Nonetheless, the conditions were the same for all animals, although the conditions may affect animals differently.

The behaviors observed are shown in Table 1 .

\section{Results}

Analyses of covariance were run in order to determine the influence of the major variables-season (breeding or nonbreeding); sex; area in which the behavior occurred; and condition of the rope [whether fresh (unmarked) or covered with the urine of foreign animals (foreign) or urine of one's own colony, either deposited recently (own fresh) or longstanding (own)]-on the five behaviors selected (urination, urine washing, rubbing, sneezing, and sniffing). Analyses of covariance were used because the animals spent differing amounts of time in the several areas of the enclosure. The covariant was the proportion of the total amount of observation time that an animal spent in a given area performing one of the selected behaviors. The statistic was chosen to eliminate biases in frequency created by the animals' being in different locations. Because of the change in $\mathrm{n}$ between the seasons, all statistical comparisons are within seasons.

Table 2 presents the composite results of the analyses. Figures 1-5 were constructed to show histograms of the mean frequency of each of the five behaviors observed as a function of the area within the enclosure (1-5), composition of the group (males when alone, females when alone, males when with females, or females when with males), and the condition of the rope (unmarked, foreign, own, and own fresh). The histograms are separated into behavior occurring during the breeding season contrasted with that occurring in the nonbreeding season.

The absence of sex and social group as discriminating variables suggest that if the deposition of urine is related to gender or mating strategies, it is related in ways that escape the net thrown by the analysis of covariance. If the scent of urine is important in the recognition of individuals by fellow Saimiri, we would not expect such factors to be so distributed as to produce a significant degree of variance in an analysis of covariance. Indeed, the use of the analysis of covariance to determine the pattern of relationships among major factors, interactions, and behavioral measures, concentrating as it does on central tendency and variance, may well mask the delicate interpersonal relationships that are characteristic of animal interactions. When individual differences are large, as we can expect in the quantification of many behaviors associated with sexual and group behavior, measures based on the expectation of normal variance may well mask what is of importance about these relationships.

Among the patterns to be seen are the following: (1) A specific section within the enclosure produces the most diverse statistically significant behaviors. (2) The differences between the seasons are dramatic in terms of the behaviors that appear as significantly different in frequency: During the breeding season rubbing, sneezing, and sniffing are prevalent significant factors; during the nonbreeding season, urination, the urine wash, and rubbing are prominent. (3) As a main factor, the urine wash is a significant behavior only as a function of the area of the enclosure and only during the nonbreeding season. (4) Sex, when examined as a main factor, is significant only for rubbing. This statistical difference appears during both seasons. (5) Those behaviors that may be associated with the leaving of an olfactory communicator (urination, the urine wash, and possibly rubbing) and those that may be associated with its reception (sneezing, sniffing, and possibly rubbing) are distributed according to such factors as the seasons of the year, the social grouping, the area of the enclosure, and the source of the urine.

Table 2

Composite Analyses of Covariance of Main Factors

\begin{tabular}{|c|c|c|}
\hline Factor & Breeding Season & Nonbreeding Season \\
\hline $\operatorname{Sex}(S)(1,5)(1,3)$ & & $\mathrm{Ru} .05$ \\
\hline Rope Condition (R) $(3,17)(3,11)$ & Sf .08 & Ur .005; Ru .001 \\
\hline \multicolumn{3}{|l|}{ Social Group (G) $(1,5)(1,3)$} \\
\hline Area of Enclosure (A) $(4,23)(4,15)$ & Ru .001; Sf .003; Sz .001 & Uw .08;Ru .01 \\
\hline \multicolumn{3}{|c|}{ Interactions } \\
\hline$S$ by $A(4,23)(4,15)$ & Ur .01; Ru .001; Sf .001; Sz .001 & \\
\hline $\begin{array}{l}S \text { by } R(3,17)(3,11) \\
S \text { by } G(1,5)(1,3)\end{array}$ & & Ur .005; Uw .08; Ru .06; Sz .08 \\
\hline$R$ by $A(12,71)(12,47)$ & $\mathrm{Sz} .03 ; \mathrm{Sf} .001$ & $\mathrm{Ru} .02 ; \mathrm{Sz} .01$ \\
\hline$R$ by $G(3,17)(4,15)$ & & Ur .01; Sz .04 \\
\hline A by $G(4,23)(4,15)$ & $\mathbf{R u} .007$ & Ur .01; Ru .001 \\
\hline$S$ by $A$ by $R(12,71)(12,47)$ & Ru .08; Sz .004 & Ur .03; Ru $.04 ; \mathrm{Sz} .04$ \\
\hline$S$ by $A$ by $G(4,23)(4,15)$ & $\mathrm{Ru} .02 ; \mathrm{Sz} .02$ & Ur $.06 ; \mathrm{Ru} .001$ \\
\hline A by $R$ by $G(12,71)(12,47)$ & & $\mathrm{Sz} .03$ \\
\hline S by R by $G(3,17)(3,11)$ & & Ur $.08 ; \mathrm{Sz} .04$ \\
\hline
\end{tabular}

Note $-U r=$ urination; $U w=$ urine wash: $R u=$ rubbing; $S f=$ sniffing; $S z=$ sneezing. The first set of degrees of freedom is for the breeding season: the second is for the nonbreeding season. 
The seasons compared. We here review the differences in frequencies of the five behaviors with special reference to season. The abbreviation B refers to the breeding season, and $\mathrm{N}$ is the symbol for the nonbreeding season.

Urination-Table 2 shows that frequency of urination during $\mathrm{N}$ has a significant main effect for rope condition. As Figure 1 shows, the chief reason for this finding is the total lack of urination recorded when the rope condition was "own." During N, urination appears often as a significant interaction. These interactions are not limited to situations involving the rope condition, but show, generally, that during $\mathrm{N}$ the frequency of urination interacts with all of the main factors. During B, frequency of urination is never a significant main factor, although it appears as a significant interaction for Sex by Area.

Urine wash-The urine wash approaches significance during $\mathrm{N}$ only at the uncomfortable, but suggestive, value of .08 . The main factor of area yields this value, as does the interaction of Sex by Rope Condition. Figure 2 shows that the rope condition "own" produces primarily urine washes and that rope condition interacts with the sex of the animal doing the urine wash. Urine washes are not uncommon during $\mathrm{B}$, but they occur under all rope conditions and are given chiefly by males when with females. The urine wash is somewhat more frequently

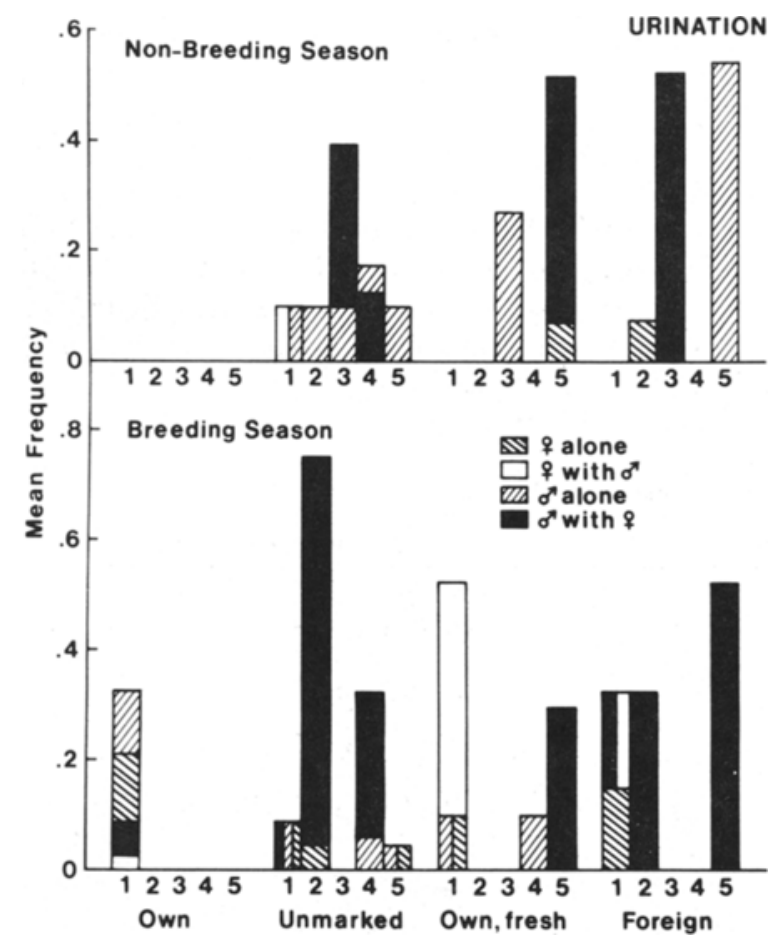

Figure 1. Mean frequency of urination by season (breeding and nonbreeding), social condition of the animals (females alone or with males, males alone or with females), origin of the urine (own, unmarked, own but fresh, foreign males), and area of the enclosure (1-5).

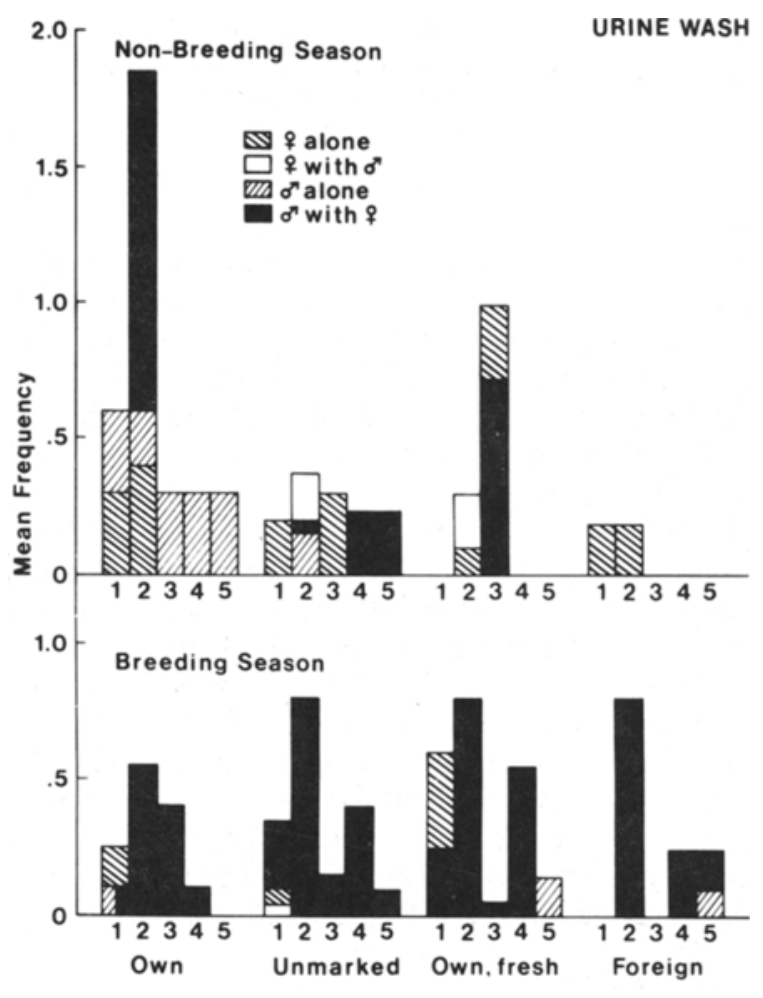

Figure 2. Mean frequency of urine washes organized as in Figure 1.

given during $B(d f=1,4 ; p=.10)$. This finding suggests that the urine wash is restricted, during $N$, to occasions when the ropes are marked by the colony's urine, but that during $B$ the males (chiefly when alone) urinewash throughout the enclosure irrespective of the rope conditions.

Sneezing-During $\mathrm{N}$, sneezing does not occur as a significant main factor. It appears in several interactions, all of which involve rope condition. From Figure 3, it can be seen that the distribution of sneezing is not a simple one. Although it is observed most often in males when with females, the frequency is remarkably high under a specific condition, viz, in females when the males, with own fresh, and in Area 2. The frequency of sneezing during B shows a different pattern. The main factor, area, is significant at .001 , and sneezing appears in two significant interactions, both involving area. The interaction between sex and area is significant at .001 , a finding to be expected from inspection of Figure 3. The most striking finding regarding sneezing is that females (when alone) show the highest frequency of sneezing during B, but males (when with females) show the highest frequency during $\mathbf{N}$.

Sniffing-During N, sniffing does not occur as a significant factor under either main factors or interactions. Figure 4 shows that the frequency of sniffing is low during N. During B, sniffing occurs as a significant main variable twice, once robustly (area at 


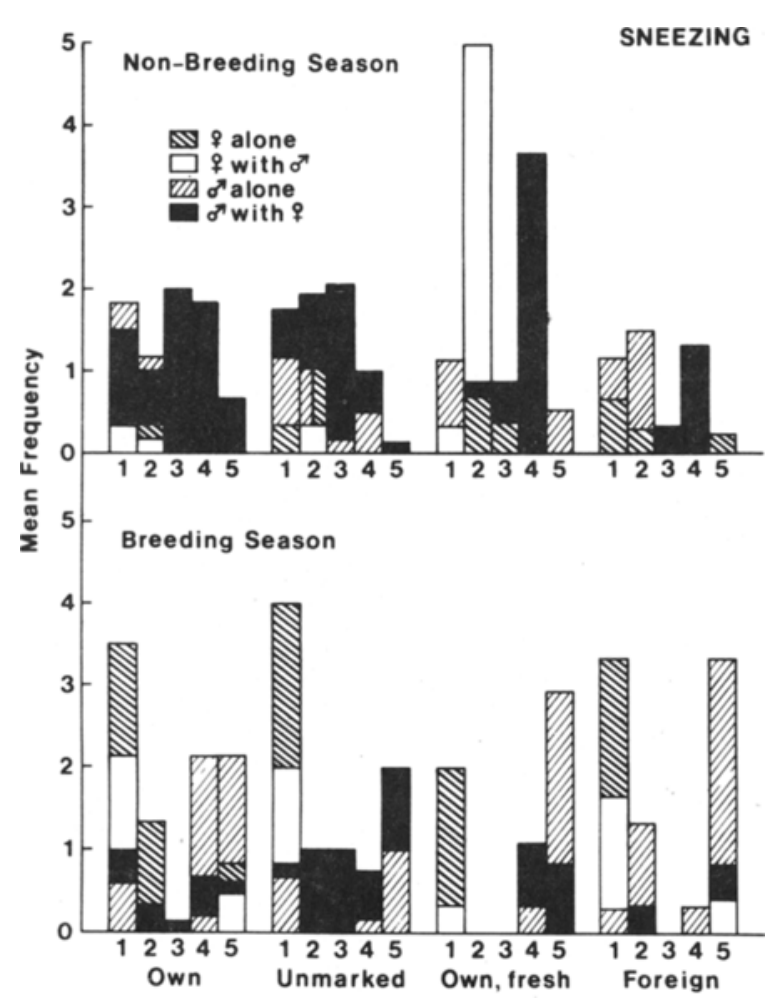

Figure 3. Mean frequency of sneezing organized as in Figure 1.

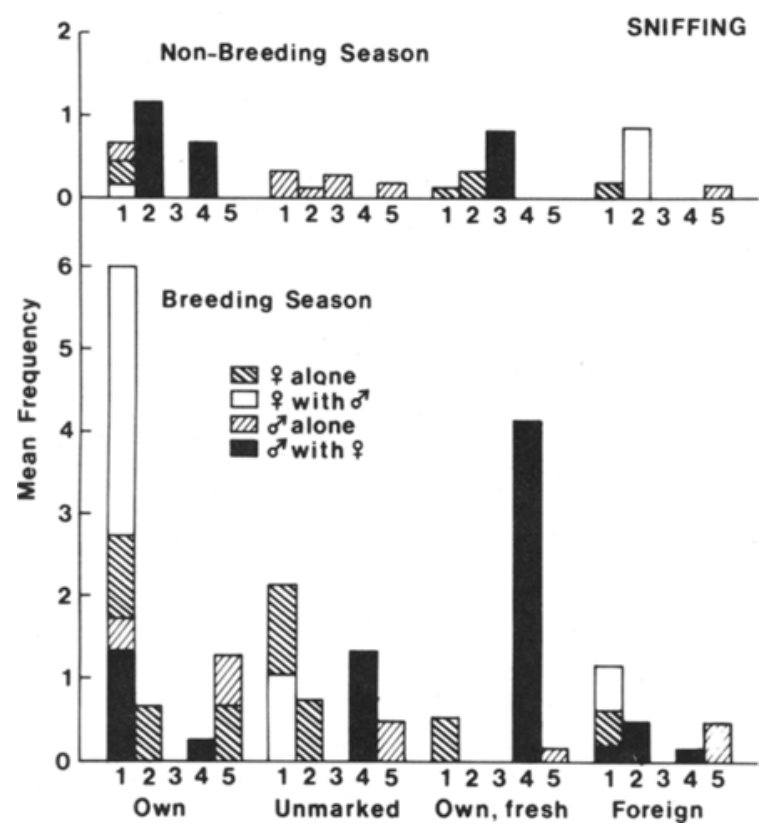

Figure 4. Mean frequency of sniffing organized as in Figure 1.

.003 ) and once only suggestively (rope condition at .08 ). The interaction of Sex by Area is significant at .001 . Figure 4 shows that during $B$ the frequency of sniffing is much greater than during $\mathrm{N}$ and that the interaction is produced chiefly by reactions to the rope condi- tion (own and own fresh, compared with foreign and unmarked) and that the sex interaction is produced by females (when with males) sniffing in Area 1 to own urine and males (when with females) sniffing in Area 4 under the urine condition of own fresh.

Rubbing-During N, rubbing is a significant factor for the main factors of sex, rope condition, and area. It also occurs commonly as a significant interaction. Figure 5 shows the dramatic differences in the distribution of rubbing as a function of season. During $\mathrm{B}$, rubbing is a significant main factor (at .001) only for area, and each of the significant interactions involving rubbing also involves area. Figure 5 demonstrates that females (when alone) and females when the males show high frequencies of rubbing in Area 1, with the male's rubbing occurring almost equally in all areas except in Area 1. During $\mathrm{N}$, rubbing is performed more by males than by females $(p=.05)$, but during $B$, in Area 1 , it is done by females $(\mathrm{p}=.001)$.

Summary-It is evident that the behaviors selected are influenced by the variables chosen for manipulation. Some effects are dramatic, others delicate and suggestive. From these, we select four findings that appear to be worth remembering as we consider the remaining comparisons-behavior as a function of

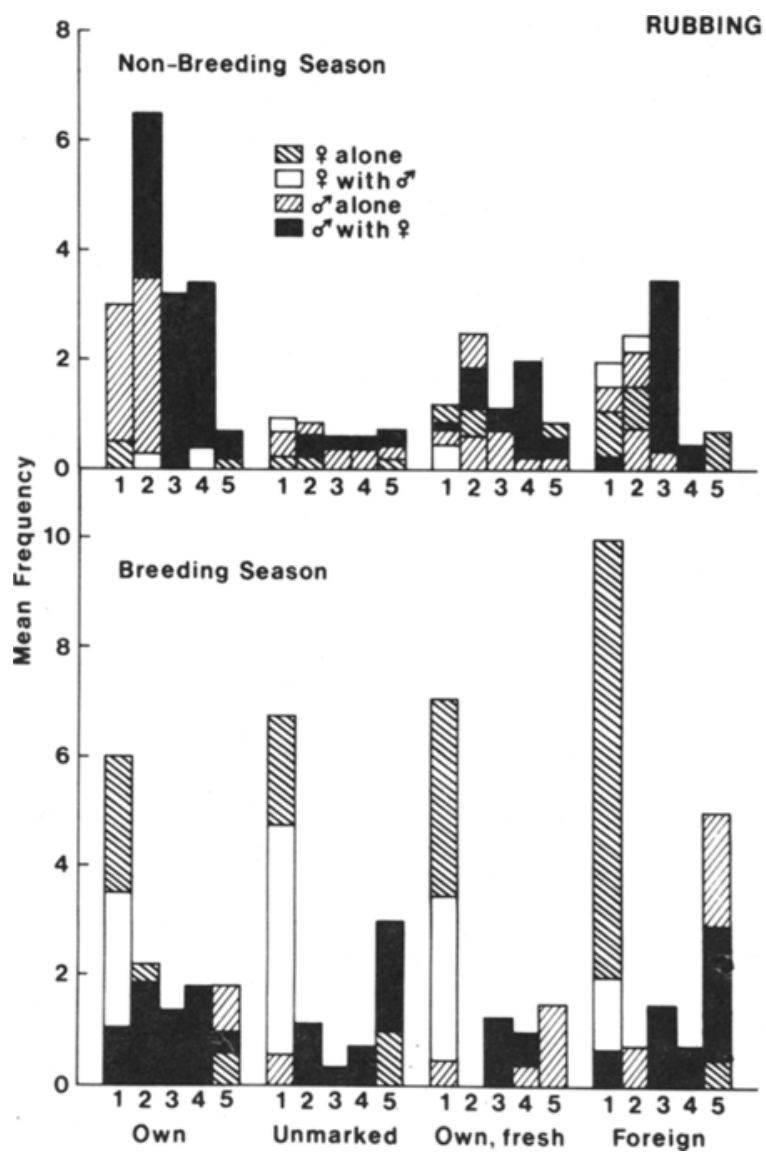

Figure 5. Mean frequency of rubbing organized as in Figure 1. 
area and rope condition. These are that: (1) during $B$, males urine-wash throughout the enclosure irrespective of the rope conditon; (2) the rope condition strongly influences the frequency of sniffing during the breeding season, with females doing so (when with males) in one area and males (when with females) doing so in another area; (3) females show the highest frequency of sneezing during $B$ (when alone), but males do so during $\mathrm{N}$ when with females; (4) during B, rubbing is strongly influenced by area. As was true of the urine wash, the sexes differ in that specific behavior is frequently demonstrated in one area by males and in another area by females.

Type of urine and social condition. In this section, we review the significant variables by concentrating on whether the urine was own, own fresh, unmarked, or foreign. Because many of these comparisons involve social condition, comment on this variable is included. We consider first the nonbreeding season ( $\mathrm{N}$ ).

Urination-During $\mathrm{N}$, as shown in Figure 1, no urinations occur when the ropes are own. The frequencies of urination under the other three rope conditions do not differ among themselves, but all differ from own $(\mathrm{df}=1,11 ; \mathrm{p}=.01)$. Significant comparisons can be made when specific social conditions are examined: (1) The frequency of urination of males in the presence of foreign urine, both when alone and when with females, is higher than that of females $(\mathrm{df}=1,11 ; \mathrm{p}=.01)$; (2) males also show an increase over females under the own fresh condition $(\mathrm{df}=1,11$; $p=.05)$; and (3) unmarked ropes also generate a significant increase in male urination over that of females, but only when compared with own ropes and not with the other conditions $(\mathrm{df}=1,11 ; \mathrm{p}=.05)$.

Urine wash-From Figure 2, it may be seen that during $\mathbf{N}$ the highest frequency of urine washes occurs when the urine is own $(\mathrm{df}=3 ; \mathrm{p}=.05)$. The fewest urine washes occur with foreign urine, although this difference $(.08)$ only approaches the usual standard of significance. By far the highest frequency of urine washes occurs in males when with females and when in Area 2. Under the own condition, when females are not present, males urine-wash in all areas; when females are present, male urine washes are limited to Area 2. Female urine washes occur principally when the ropes are own fresh. Males do not urine-wash at all under foreign.

Sneezing-During $\mathrm{N}$, there is no significant difference in frequency of sneezing as a function of the main factor, rope condition (Figure 3), although some interactions do occur (Group by Rope Condition $=.04$; Sex by Area by Rope Condition $=.04$; Area by Rope Condition by Group $=.03$ ).

Sniffing-As was true of sneezing, there is no significant difference among the groups as a function of type of urine or social condition (Figure 4).

Rubbing-The frequency of rubbing is signif- icantly higher under the own condition $(\mathrm{df}=3 ; \mathrm{p}=.03)$. When social condition is examined, we find that males (whether alone or with females rub more frequently than females $(\mathrm{df}=1 ; \mathrm{p}=.001)$.

Summary-During N, most significant differences in frequency of behavior occur under the own condition: No urination occurs, but there is a high frequency of urine washes. The urine washing is done by males, principally in one area. Rubbing is higher under the own condition. It, too, is principally a male activity. No differences appear when sneezing or sniffing are considered.

We now examine information on the source of urine and social grouping during the breeding season, $\mathrm{B}$.

Urination-During B, urination occurs under the own condition, although in only one area. The differences in frequency of urination among the groups are not significant. The chief difference between the seasons is that urination does not occur under own during $\mathrm{B}$, but does so, in a single area, during $\mathrm{B}$.

Urine wash-During $\mathrm{B}$, there is no significant difference among groups as a result of rope condition. The high incidence of the male urine wash has been noted in the previous section. It is widespread, occurring in all rope conditions and in all areas.

Sneezing-Although sneezing occurs under all rope conditions, the frequency of sneezing on the part of females is great st when they are alone $(\mathrm{df}=1,5 ; \mathrm{p}=.08)$.

Sniffing-When the ropes are marked by own, the frequency of sniffing is greater than in any other rope condition ( $d f=3 ; p=.03)$. Such sniffing is shown by females when with males $(\mathrm{df}=1,11 ; \mathrm{p}=.01)$, followed in degree of difference (at .08) by females when alone. When the ropes are fresh, however, the frequency of sniffing is greater among males (when with females) $(\mathrm{df}=4 ; \mathrm{p}=.03)$, a finding attributable to the frequency of male sniffing in Area 4.

Rubbing-During $\mathrm{B}$, there is a dramatic change in frequency from that noted during $\mathbf{N}$. First, rubbing is observed most frequently when females are alone $(\mathrm{df}=1,5 ; \mathrm{p}=.01)$ and next in frequency by females when with males $(\mathrm{df}=1,5 ; \mathrm{p}=.05)$. When done by females, rubbing is done exclusively in Area 1. Second, when males rub, they do so in Area 5, both when alone and when with females $(\mathrm{df}=1,23 ; \mathrm{p}=.05)$.

Summary-The most consistently striking differences during $\mathrm{B}$, compared with $\mathrm{N}$, concern sexual behavior. Males urine-wash throughout the enclosure, and females both rub and sniff when alone and when with males, chiefly in Area 1.

Location of the behaviors. The analysis of covariance, used to determine significant main factors and interactions, was the statistic of choice because it accounts for differences in frequencies related to the variable of location alone. We here review the 
qualitative differences in frequencies of behavior that occur as a function of area of the enclosure. We follow the procedure of describing the behaviors independently, first for the nonbreeding season ( $N$ ) and second for the breeding season (B).

Urination-During N, Areas 3 and 5 are used more frequently than other areas for urination (Figure 1), chiefly by males, whether alone or with females.

Urine wash-The urine wash performed by males under the own condition occurs mainly in Area 2. Otherwise, no differences in location for the urine wash occur during $\mathrm{N}$.

Sneezing, sniffing, and rubbing-Although some interactions occur between location and type of urine, location is, in general, not a significant factor affecting any of these behaviors during $\mathrm{N}$.

During B, several behaviors appear frequently in one area but not in others.

Urination-The frequency of female urination is greatly increased in general. More particularly, females urinate in Area 1 (under the own condition) both when alone and when with males. Males (when with females) use Area 1 somewhat, but most frequently use Areas 2, 4, and 5. Males now avoid Area 3, the area most used for urination during $\mathrm{N}$.

Urine wash-Area 3 is little used for urine washes, although this was the favored area during N. Male urine washes (when with females) occur in all areas, irrespective of rope condition. Figure 3 shows the shift in frequency between $\mathrm{B}$ and $\mathrm{N}$ for male urine washes.

Sneezing-During B, females, when alone, sneeze chiefly in Area 1, while males (when alone) do so in Area 5. When each sex is with the other, the same pattern occurs, but less frequently: females sneeze in Area 1 and males sneeze in Area 5.

Sniffing-Females (whether with males or alone) exhibit most of the sniffing, and it occurs in Area 1, chiefly under the own condition. Males (when with females) show a high frequency of sniffing in Area 4, but under a single condition, when the ropes are own fresh.

Rubbing-Females, both when alone or with males, show a very high frequency of rubbing in Area 1. Male rubbing is not distinguished by location except under the condition of foreign urine when Area 5 is much used.

Summary - The comparative frequency with which behaviors appear in each area is greatly affected by whether or not it is the breeding season. Although the importance of location is often found to interact with condition of the rope, it is noteworthy that the different sexes use different areas for selected behaviors during the breeding season. For urination and urine washing, the males abandon the areas used in $\mathrm{N}$, and during $\mathrm{B}$ urinate and urine-wash in all other areas of the enclosure. Females show high frequencies of sniffing, sneezing, and rubbing in Area 1.

\section{General Summary of Experiment 1}

Behavioral responses to urine depend upon two factors: first, whether it is breeding season or not and, second, whether the urine is from members of one's own troop or not. The most general pattern is this: During the breeding season, males urine-wash throughout the enclosure, and females increase the frequency of their sneezing, sniffing, and rubbing. Most of this occurs in Area 1.

During the nonbreeding season, the pattern of urination is more restricted: males urinate principally on own ropes and on those marked by the urine of foreign animals, and they do so in Areas 3 and 5. Area 3 is abandoned during the breeding season and never used by males for urination. In the nonbreeding season, the urine wash is observed principally in males on own ropes, in contrast to the breeding season, when the urine washes by males occur throughout the enclosure. Sneezing and sniffing do not vary, but rubbing is affected by the main variables.

Males do not urinate on their ropes during the nonbreeding season, but do so (as do animals under all other grouping conditions) during the breeding season. During the nonbreeding season, males urinewash chiefly when with females and chiefly in Area 2, but during the breeding season they urine-wash throughout the enclosure. Sniffing, sneezing, and rubbing all show dramatic changes in frequency as a result of the change in season. The frequency of sniffing is low during the nonbreeding season but increases among females during the breeding season. Sneezing, too, is more frequently observed among females during the breeding season. Rubbing varies by the season in terms of where it occurs. During breeding season, females rub in Area 1 and males rub in Area 5. During the nonbreeding season, the frequency of rubbing does not differ in terms of location.

These findings suggest that it is helpful to think of the deposition of urine (through urination and urine washing) as distinct from the apparent reaction to it (sneezing, sniffing, and rubbing). When this distinction is made, the behaviors of the sexes demonstrate different characteristics in terms of the effects of the seasons and, to a seemingly slighter degree, in terms of the condition of the rope, the social grouping, and the location. Those behavior patterns that shift most significantly differ between males and females. For males, the behaviors that show significant differences involve the depositing of urine (urination, urine wash, and rubbing). For females, the most conspicuous are those that may be related to the odor of urine (sneezing and sniffing). Rubbing may have the function of both distributing and assisting perception of a stimulus, and the sexes rub chiefly in separate areas during the breeding season.

Although foreign urine provokes urination and urine marking among many species, its effect on 
Saimiri depends upon season and location. Urine washes to foreign urine are minimal (and done by females when alone) during the nonbreeding season, but during the breeding season the foreign urine induces urine washing as often as does any other rope condition. The effect of the presence of foreign urine is urination in specific areas of the enclosure; some areas are ignored, while others show increased frequencies of urination and urine washing under specific social groupings (e.g., males with females in Area 3, but males when alone in Area 5 during the nonbreeding season). Foreign urine appears to have no special effect on sneezing or sniffing. Rubbing increases in frequency when the urine is foreign, but not significantly so. Both the urine wash and urination are influenced by the own condition, but the frequency is lower under conditions of foreign urine. There is no support for the notion that Saimiri urinemark in response to foreign urine: Indeed, it would appear that their behavior is inhibited by the urine of foreign animals.

\section{EXPERIMENT 2}

When social behavior is examined in an enclosed environment as in Experiment 1, there is a strong possibility that the results observed in a restricted perhaps enhanced by the animal's being in a restricted space. Urine may offer an attractive means of communicating under restricted conditions, but have little use under unrestricted conditions. Or, just as likely, it may have greater use under unrestricted conditions.

Although it was impossible to reproduce the design used in Experiment 1 under totally unrestricted, or field, conditions, we arranged an experiment designed to determine whether Saimiri in the field can distinguish the urine of their own troop members from that of foreign Saimiri from unfamiliar troops. This variable was chosen both because it lends itself to manipulation under field conditions and because one of the most impressive findings from Experiment 1 was the evidence that Saimiri distinguish the urine of their own troop (own) from that of foreign animals.

\section{Method}

The study site was monkey Jungle, Goulds, Florida. Located 23 miles south of Miami and 10 miles north of the Everglades $\left(25^{\circ} 33^{\prime} \mathrm{N}\right)$, the jungle is a commercial center that contains a 1.6-ha (approximately 4-acre) rain forest. In 1960, Saimiri sciureus were introduced to this forest along with certain other species of New World primates. Saimiri flourished in this environment, so much so that the original population of monkeys has increased to more than 200 at the most recent count. The rain forest is surrounded by a strip that has been cleared of flora and a 7 -ft fence, now electrified, that encourages the monkeys to remain within the forest.

The rain forest is fundamentally a Florida subtropical hardwood hammock with an aerial sprinkling system that supplements local rainfall to total approximately $180 \mathrm{in}$. per year. To the hammock have been added hundreds of species of South American palms,
Table 3

Design for the Field Study

\begin{tabular}{llc}
\hline Phase & \multicolumn{1}{c}{ Condition } & Duration \\
\hline I & Baseline 1 & 3 \\
II & Foreign Urine & 5 \\
III & Baseline 2 & 3 \\
IV & Experiment 1 Urine & 5 \\
V & Baseline 3 & 3 \\
VI & Experiment 2 Urine & 5 \\
\hline
\end{tabular}

Note-Durations are given in days.

philodendrons, ficus, and the like. (For a detailed description, see Baldwin, 1969; Fontaine \& DuMond, 1977.) Because visitors are encouraged to walk along the trails through the forest, the Saimiri are habituated to the presence of human beings. They are fed at a known feeding station several times each day. As was true of the Saimiri in the enclosure, these animals are not dependent upon the environment for food.

The Saimiri population is divided into three troops (A, B, and $\mathrm{C}$ ), each containing adult male, female, and juvenile subgroups, and, at times, infants. The troops had no specific home areas, but roamed as units. During the year in which these observations were made, a fourth troop began to form. Because of our uncertainty as to its becoming a stable group, its members were not treated as a separate group during the period of observation. Throughout the annual cycle, the troops exhibit consistent patterns of movement through the rain forest. These patterns amount to a moving territory, for there is an evident ranking among the troops in terms of which yields locations to which other. Aggression usually ensues if the males of one troop approach another troop.

Some animals were tagged and others were recognizable because of obvious scars and the like. We believe that we were able to identify $75 \%$ of the adult Saimiri in the forest.

Procedure. We chose two trees (Area 1 and Area 2) on which to deposit Saimiri urine, based on the observation that they were in locations through which all troops usually passed during the day. The place selected for the deposition of urine was a $6 \times 6 \times 6 \mathrm{~m}$ area on branches $9 \mathrm{~m}$ above the ground.

The urine came from two sources, members of the forest troops and unknown Saimiri. Urine from the first source was collected by capturing males from two troops and placing them in metabolism cages for 6 days or until $50 \mathrm{ml}$ of urine had been collected. The urine from animals within a given troop was pooled to provide a group sample. Urine of foreign animals was taken in an identical fashion from male Saimiri living in the enclosure of the Bucknell colony. With each group, care was taken to separate urine collected during the breeding and the nonbreeding seasons.

The experimental design used to determine when urine was to be placed in the areas is shown in Table 3 . An experimenter climbed to the area in the early morning and, using a sponge mop, spread a thin layer of the appropriate urine on the top surface of each horizontal branch in the area. Twenty milliliters of urine was placed on each area each day. Before the baseline measurements were taken, the trees were washed at daybreak in an attempt to remove earlier marks.

The procedure was followed during both the breeding and nonbreeding seasons. Observations were recorded on maps of the areas that used specific trees as location markers. Observations were $1 \mathrm{~h}$ in length. When a monkey entered the area, the observer recorded the monkey's identification number, the location, and the duration and type of behavior. During the breeding season, $16 \mathrm{~h}$ of observation were completed each day; during the nonbreeding season, it was $10 \mathrm{~h}$. On days during which heavy rain fell, a standard policy was followed: If the rain began before, or up until $5 \mathrm{~min}$ after, the beginning of a scheduled observation period, the observations for that period were cancelled. If the rain began more than 5 min after the period had begun, the observations were continued for the remainder of the period. 
Table 4

Composite Analyses of Variance

\begin{tabular}{lll}
\hline \multicolumn{1}{c}{ Factor } & \multicolumn{1}{c}{ B } & \multicolumn{1}{c}{$\mathrm{N}$} \\
\hline Sex $(\mathrm{S})(1,60)$ & Ukw .001; Sf .05; Ru .05 & Ru .05 \\
Area $(A)(1,60)$ & Ru .01 & Uw .01 \\
Troop $(T)(2,60)$ & Ukw .05; Ru .05 & \\
& Interactions & \\
S by A $(1,60)$ & & \\
S by T $(2,60)$ & Ukw .01 & \\
A by T $(2,60)$ & Ru .001 \\
S by A by T $(2,60)$ & & \\
\hline
\end{tabular}

Note $-B=$ breeding season; $N=$ nonbreeding season; $U k w=$ urine kick wash; $R u=$ rubbing; $U w=$ urine wash.

\section{Results and Discussion}

Table 4 shows the factors and interactions resulting from an analysis of variance on each of the behaviors recorded. Separate analyses were run for the breeding season and the nonbreeding season. Differences are most frequent in the breeding season, and the urine kick wash (Ukw in Table 4) appears as a significant factor. This behavior was not observed in the laboratory enclosure, but as described in Table 1 .

Some behaviors reported in Table 2, in which differences in behavior in the enclosure were reported, do not appear under field conditions. Urination, for example, was observed often in the laboratory and appeared as a significant factor in many combinations of the experimental variables, but it does not appear as a significant factor in the field. Indeed, it is rarely observed at all: Those urinations observed occurred chiefly in the breeding season and were performed by females. Obviously urination is not restricted to one season of the year or to one sex. This finding points clearly to one difficulty of field observation: Whether it is because of the obvious presence of a human observer, difficulty in locating animals, or changes in visibility caused by seasonal factors, observations in the field may be unreliable, and therefore, the assessment of the degree of reliability is unsatisfactory. Concerning the presence of a human observer, Candland et al. (1972) have shown that Saimiri that had been exposed to the presence of an observer for several years still showed behavior patterns that were different when human beings were present from when observation was conducted by closed-circuit television, suggesting that Saimiri do not habituate to the presence of a human observer even after 3 years of such experience.

Urine washes were observed in the nonbreeding season primarily in Area $1(\mathrm{df}=1,60 ; \mathrm{p}=.01)$. They were performed by males and females of all troops. This finding is analogous to that from the laboratory enclosure, where urine washes showed a significant difference in frequency during the nonbreeding season only as a function of area. That the urine wash appears to differ significantly in frequency during the non- breeding season in both field and enclosure demonstrates its relevance to particular areas. All of the urine washes that occurred in Area 2 during the breeding season occurred under the "foreign" condition. These urine washes may have been unrelated to the dispersion of scent, instead being principally a response to the urine of foreign animals, as found in Experiment 1.

The urine kick wash, a behavior rarely seen in the laboratory enclosure, was common in field conditions during the breeding season, when it was performed principally by males $(\mathrm{df}=1,60 ; \mathrm{p}=.001)$. It was observed only once during the nonbreeding season. The majority of kick washes were performed by the males of Troop $1(\mathrm{df}=2,60 ; \mathrm{p}=.01)$, the animals lowest in the hierarchy of troops during this season. This information may indicate an increase in arousal among these lower ranking animals when in the vicinity of troops of higher rank. Alternatively, of course, it may reflect a behavioral response far more complex, one involved in the relationship between a troop's rank and its use of a particular location.

Sneezing, a behavior common in the laboratory enclosure, was not seen in the field during the nonbreeding season and was observed only rarely during the breeding season. Why should sneezing be common in the laboratory enclosure and not in the field? One possibility is that the enclosure produces so many smells that recognition is made difficult. Sneezing may assist detection. In the field, odors are scattered, thereby decreasing the need to enhance reception of an odor by sneezing and sniffing. In the field, sniffing is more frequent than sneezing. In the nonbreeding season (in enclosure and in field), occurrences of sniffing were few, but they were observed in both females and males. In the breeding season, the overall frequency of sniffing increased and a sex difference emerged; in the field, males sniffed significantly more than females $(\mathrm{df}=1,60 ; \mathrm{p}=.05)$, but in the laboratory, females sniffed more than males. It is unlikely that either sneezing or sniffing is a sexrelated trait. The explanation for the sex difference in frequency must lie in the different pressures imposed by the living conditions.

Rubbing, which we have interpreted as either aiding the spreading of the urine or increasing the likelihood of reception of its scent, also differs in frequency between field and enclosure. In the field setting, during the nonbreeding season, all of the observed rubs were performed by males, a frequency differing from that of female rubs $(\mathrm{df}=1,60 ; \mathrm{p}=.05)$. All three troops showed a similar dispersion of rubs in both areas. In the breeding season, on the other hand, rubs were performed primarily in Area $1(\mathrm{df}=1,60$; $\mathrm{p}=.01)$, and again primarily by males $(\mathrm{df}=1,60$; $\mathrm{p}=.05$ ). A significant interaction between area and troop occurred $(\mathrm{df}=2,60 ; \mathrm{p}=.001)$, showing, upon 
analysis, that members of Troop A rub in Area 1 and members of Troop B rub in Area 2. Troop C rubs in no specific area. In the enclosure, the dispersion of rubbing is analogous. Males rub more frequently than females in both seasons and rubbing is more frequent in one area than in another.

To summarize the results from the field observations: (1) one behavior that was never observed in the enclosure-the urine kick wash-is seen in the field; (2) urination and rubbing show frequency patterns that differ as a function of season in both enclosure and field; (3) while sneezing is common in the laboratory, it is rarely observed in the field; (4) the frequency of field observations demonstrates problems with reliability not encountered in the enclosure, as shown, for example, in the observed frequencies of urinations.

\section{GENERAL DISCUSSION}

\section{What is Communicated by Urine}

The stringent view which holds that meaning is defined by the response of other beings, suggests several meanings that Saimiri appear to find in urine. First, urine communicates information as to whether the environment contains the odors of their troop or of those foreign to it. Their reception of such information implies that Saimiri have as yet unestimated abilities to detect and recognize olfactory stimuli. A study of the abilities of chickens had indicated that an adult cock can remember up to 100 other chickens (Douglis, 1948). If it is know that the chicken has such abilities, it should not be astonishing to discover that Saimiri and other New World primates are able to detect and remember far larger sensory configurations than has heretofore been supposed.

That the state of urine available-whether foreign, known, recently marked, or long-standingcan be a determinant of Saimiri behavior supports the suggestion that urine provides monkeys with information regarding location, the nature of the communicator, and the recency of the deposit. Although it can be shown only indirectly from Experiment 1 and somewhat more demonstrably in Experiment 2 that Saimiri urine communicates information about location, the large number of interactions involving location and the consistent patterns of certain areas being used for certain behaviors surely suggest this conclusion.

The differing responses to recent vs. long-standing urine might reflect nothing more than habituation to the stimulus or loss in its power. If so, we could expect the two responses to be merely versions of one another, differing only in frequency. In fact, the two conditions produce different behavioral patterns on the part of males and females and during the breeding and nonbreeding seasons, suggesting that recency itself has different meanings depending upon the animal's sex, the social condition, and the season.

Even a rough consideration of meaning requires analysis at the level of interactions between individual animals. Although the data here reported show the importance of some major factors on behaviors associated with urine, they do not permit the sequential analysis necessary to relate meaning to interactions between animals.

\section{Other Uses of Urine as a Communicator}

Animals that produce pheromones have found optimal benefit in developing distinct glands that secrete specific chemicals. Presumably this strategy is suggested when whatever is to be communicated demands immediate attention. As is true of most mammals, Saimiri have no known specialized scent gland. This suggests that the use of urine to communicate is opportunistic. Urine has many advantages as a conveyor of information: It is readily available and, to some degree, under voluntary control. Because it changes constantly in composition, it may communicate information regarding the internal state of the producer. This is a doubly intriguing hypothesis, for one of the more interesting components of urine is adrenalin which is thought to be secreted in response to a variety of hormonal activities that accompany stress. It has not been shown, however, that they are odiferous.

An obviously probable use of urine is to provide information on sexual preparedness, and the strong differences in behavior that we found between the breeding and nonbreeding seasons tend to support this idea. The dramatic changes in frequencies of selected behaviors on the part of males and females, either alone or in a heterosexual group, surely suggest that something is being communicated about sex. But sex, in mammals, is a two-animal affair. Thus, methods of analysis that are based on central tendencies are certain to evaluate mistakenly or to overlook the skewness demanded by the two-animal nature of sex. Clarification of the role of urine sexual communication must await sequential methods of analysis of individual behavior.

\section{Environmental Conditions that Affect the Deposition of Urine}

Of the factors introduced into both the enclosure and field study, it would appear that season of the year is the most influential. The immediate causes of the seasonal variation in behavior and physiology are unknown, although many factors, including humidity and rainfall, have been suggested. Saimiri that have been removed from the equatorial areas in which they normally live show a slow adaptation to the northern latitudes. In our laboratory, Saimiri require some years to reestablish their original breeding cycle. This slowness to adapt suggests that the determiners of seasonal behavior have an endogenous cue and that they are strong within individuals. 
We do not know whether changes in the quality of urine might have reciprocal effects on other animals. Males become fatted, but it is unclear whether their being fatted cues the females' receptivity or whether the receptivity cues the fattedness. If the latter, it might well be the qualities of the urine that signal receptivity by providing information on the females' hormonal state.

A second significant environmental condition is whether an animal is with members of its own sex or with a troop containing both sexes. Differences were found in the frequencies of certain behaviors as a function of this condition. The implication is that the responsiveness of Saimiri to the urine of other Saimiri depends, in part, on who is around. This suggestion, in turn, suggests that Saimiri have a more elaborate ability to recognize and detect differences among troop members than has been suspected.

The final environmental factor of note is the area in which the various behaviors, including urination and the urine wash, occur. Data from the enclosure suggest large differences in frequencies as a function of where the behavior occurs, but data from the field make no such suggestion. This latter conclusion is uncertain, however, since location was not varied independently in the field study.

\section{Generality of the Findings}

Two questions arise when we turn to the issue of the generality of the findings. The first concerns generality to other species: Are behaviors such as urine washing characteristic of other Platyrrhini or other primates? The second concerns generality between the study environments, laboratory enclosure and field.

Whether other species use urine to convey or receive information is uncertain, principally because the issue has been examined mostly in those species suspected of having specialized pheromones. That urine itself can be the messenger, one that requires no specialized receptor, suggests that many animals, primates and others, may use this form of communication. The need for systematic studies is evident.

The second question concerns generality between enclosure and field. It is a mistake to think of the field as necessarily offering more freedom of movement or a lower population density than the laboratory enclosure. Although the population density in the laboratory appears to be high if one calculates animals per area, it is actually no higher than it is in the field, for there animals do not disperse, but instead form compact social groups. Laboratory animals maintained as in this study have far fewer pressures than do those in the field. They are provisioned with food and water (eliminating investment in foraging and acquiring water), and there are no predators. The field situa- tion used here is notably less severe in terms of the prevalence of selective pressures than that found in natural jungles.

Despite the similarities between the two environments, it is nonetheless noteworthy that there is some evidence that urine serves functions in the field different from those served in the enclosure. In the field, it apparently serves to assist animals in distinguishing their own troop from others. Whether it also serves other functions, such as those discovered in the enclosure, is not evident. We can conclude that Saimiri do not respond to stimuli in rigid, automatic ways; rather, they are capable, as are most vertebrates, of the opportunistic use of available stimuli. The deposition of urine is one such stimulus.

\section{REFERENCES}

BALDwin, J. D. The social behavior of adult male squirrel monkeys in a semi-natural environment. Folia Primatologica, 1968, 9, 281-314.

BALDwin, J. D. The ontogeny of social behavior of squirrel monkeys (Saimiri sciureus) in a semi-natural environment. Folia Primatologica, 1969, 11, 36-79.

CANDLAND, D. K. Changes in heart rate during social organization of the squirrel monkey (Saimiri sciureus, Iquitos). Proceedings of the 3rd International Congress of the Primatological Society, Zurich, 1970. Basel: Karger, 1971.

Candland, D. K., Bryan, D. C., Nazar, B. L., Kopf, K. J., \& SENDOR. M. Squirrel monkey heart rates during formation of status orders. Journal of Comparative and Physiological Psychology, 1970, 70, 417-423.

Candland, D. K., Dresdale, L., Leiphart, J., \& Johnson, C. Videotape as a replacement for the human observer in studies of nonhuman primate behavior. Behavior Research Methods \& Instrumentation, 1972, 4, 24-26.

Castell, R. B., \& Heinrich, B. Rank order in a captive female squirrel monkey colony. Folia Primatologica, 1971, 14, 182-189.

Castell, V. R., \& Maurus, M. Das sogenannte Urinmarkieren von Totenkopfaffen (Saimiri sciureus) in Abhängigkeit von umweltbedingten und emotionalen Faktoren. Folia Primatologica, 1967, 6, 170-176.

Douglis, M. B. Social factors influencing hierarchies of small flocks of the domestic hen: Interaction between resident and part-time members of original flocks. Physiological Zoology, $1948,21,147-182$.

DuMond, F. V., \& Hutchinson, T. C. Squirrel monkey reproduction: The "fatted" male phenomenon and seasonal spermatogenesis. Science, 1967, 158, 1467-1470.

EPPLE, G. Olfactory communication in South American primates. Annals of the New York Academy of Science, 1974, 237, 261-278. (a)

EPple, G. Pheromones in primate reproduction and social behavior. In W. Montague \& W. A. Sadler (Eds.), Advances in behavioral biology (Vol. 2). New York: Plenum, 1974. (b)

Fontaine, R., \& DuMond, F. V. The Red uakari in a seminatural environment: Potentials for propagation and study. In H. S. H. Prince Rainier \& G. H. Bourne (Eds.), Primate conservation. New York: Academic Press, 1977

Hennessy, M. B., Coe, C. L., Mendoza, S. P., Lowe, E. P., \& Levine, S. Scent-marking and olfactory investigatory behavior in the squirrel monkey (Saimiri sciureus). Behavioral Biology, 1978, 24, 57-67.

Hill, W. C. O. Comparative anatomy and taxonomy-Primates (Vol. 4). Edinburgh: University Press, 1960. 
HiLL, W. C. O. Comparative anatomy and taxonomy-Primates (Vol. 5). Edinburgh: University Press, 1962.

Hopf, S., Hartman-Wiesner, E., Kuhlmorgen, B., \& Mayer, S. The behavioral repertoire of the squirrel monkey (Saimiri sciureus). Folia Primatologica, 1974, 21. 225-249.

Jones, R. B., \& Nowell, N. W. The effect of urine on the investigatory behavior of male albino mice. Physiology \& Behavior, 1973, 11, 35-38.

Jones, R. B., \& Nowell, N. W. Effects of androgen on the aversive properties of male mouse urine. Journal of Endocrinology, 1974, 60, 19-25.

LatTA, J., Hopf, S., \& Ploog, D. Observations on mating behavior and sexual play in the squirrel monkey (Saimiri sciureus). Primates, 1967, 8, 229-246.

Milton, K. Urine-rubbing behavior in the mantled howler (Alouatta palliata). Folia Primatologica, 1975, 23, 105-112.

Moynihan, M. The New World primates. Princeton, N.J: Princeton University Press, 1976.

Napier, J. R., \& Napier, P. H. A handbook of living primates. London: Academic Press, 1967.

Ploog, D., \& Maclean, P. D. Display of penile erection in squirrel monkeys. Animal Behaviour, 1963, 11, 32-39.

Sebeok, T. A. (Ed.). Animal communication. Bloomington: Indiana University Press, 1968.

Seitz, E. Die Bedeutung geruchlicher Orientierung beim Plumplori, Nycticebus coucang Boddaert, 1785. Zeitschrift für Tierpsychologie, 1969, 26, 73-103.
Sмiтh, W. J. The behavior of communicating. Cambridge, Mass: Harvard University Press, 1977.

STEVenson, M. F. Studies on the common marmoset (Callithrix jacchus) in the laboratory and in the natural environment In D. M. Fragaszy \& J. L. Vogt (Eds.), Laboratory and field approaches to social behavior in New World primates. Basel, Switzerland: Karger, in press.

Talmage-RIgGs, G., \& Anschel, S. Homosexual behavior and dominance hierarchy in a group of captive female squirrel monkeys (Saimiri sciureus). Folia Primatologica, 1973, 19, 61-72.

Thiessen, D., \& RICE, M. Mammalian scent gland marking and social behavior. Psychological Bulletin, 1976, 83, 505-539.

Thorington, R. W. Observations of the squirrel monkey in a Colombian rainforest. In L. A. Rosenblum \& R. W. Cooper (Eds.), The squirrel monkey. New York: Academic Press, 1968.

VogT, J. L. Spatial analysis of social structure in Saguinus fuscicollis. In D. M. Fragaszy \& J. L. Vogt (Eds.), Laboratory and field approaches to social behavior in New World primates. Basel, Switzerland: Karger, in press.

WALKER, E. P. Mammals of the world (Vol. 1; 3rd ed.). Baltimore: Johns Hopkins University Press, 1975.

Winter, P., Ploog, D., \& Latta, J. Vocal repertoire of the squirrel monkey (Saimiri sciureus): Its analysis and significance. Experimental Brain Research, 1966, 1, 359-384.

(Received for publication May 25, 1979; revision accepted November 30,1979 .) 